\title{
Blue organic light-emitting diodes based on pyrazoline phenyl derivative
}

\author{
P. Stakhira ${ }^{a, *}$, S. Khomyak ${ }^{a}$, V. Cherpak ${ }^{a}$, D. Volyniuk ${ }^{a}$, J. Simokaitiene $^{b}$, A. Tomkeviciene ${ }^{b}$, \\ N.A. Kukhta ${ }^{\text {b J.V. Grazulevicius }}{ }^{\text {b }, ~ A . V . ~ K u k h t a ~}{ }^{c}$, X.W. Sun ${ }^{c}$, H.V. Demir ${ }^{c, d}$, Z. Hotra ${ }^{\text {a, e }}$, L. Voznyak ${ }^{\text {a }}$ \\ a Lviv Polytechnic National University, S. Bandera 12, 79013 Lviv, Ukraine \\ ${ }^{\mathrm{b}}$ Department of Organic Technology, Kaunas University of Technology, Radvilenu pl. 19, LT-50254 Kaunas, Lithuania \\ ' School of Electrical and Electronic Engineering, Nanyang Technological University, Nanyang Avenue, 639798 Singapore \\ d UNAM Department of Electrical and Electronic Engineering, Department of Physics, Bilkent University, Bilkent, 06800 Ankara, Turkey \\ e Rzeszów University of Technology, W. Pola 2, Rzeszów 35-959, Poland
}

\section{A R T I C L E I N F O}

\section{Article history:}

Received 14 September 2011

Received in revised form

13 December 2011

Accepted 20 December 2011

Available online 21 January 2012

\section{Keywords:}

Organic light emitting diode

Blue emitting

Vacuum deposition

Pyrazoline derivative

Carbazole derivates

\begin{abstract}
A B S T R A C T
The results of an experimental study of the electroluminescent device made of ITO/CuI/2,6di-tert.-butyl-4-(2,5-diphenyl-3,4-dihydro-2H-pyrazol-3-yl)-phenol (HPhP)/3,6-Di(9-carbazolyl)-9-(2ethylhexyl) carbazole (TCz1)/Ca:Al with efficacy up to $10.63 \mathrm{~cd} / \mathrm{A}$ are presented. HPhP provides blue emission with a peak wavelength at $445 \mathrm{~nm}$. The layer of TCz1 acts as an electron-transporting layer. In the framework of density functional theory (DFT) approach the geometry configuration and energy levels of HPhP are found being in a good agreement with spectral and cyclic voltammogram data.
\end{abstract}

(C) 2011 Elsevier B.V. All rights reserved.

\section{Introduction}

One of the key steps towards the development of efficient organic light-emitting diodes (OLED) relies on the choice of a suitable organic emitter. This material has to form thin homogeneous amorphous films, whilst avoiding forming various uncontrollable complexes (charge transfer complexes, exciplexes, etc.) with neighbouring molecular layers and electrodes to prevent exciton quenching. In addition it should exhibit a high luminescence quantum yield [1]. Usually, OLEDs based on organic materials emitting in the blue spectral region still suffer low levels of efficacy and short lifetimes as compared to those emitting in green and red. Blue emitting materials have a wide forbidden gap [2], making it difficult to inject charge carriers from electrodes [3]. Moreover, such materials are relatively unstable under applied electric field and atmospheric factors [4]. Blue emitting OLEDs have been extensively studied for the last ten years and a lot of new high performance molecules have been proposed based on different approaches [2,5-10]. However, the performance characteristics are still lower than for green and red emitting OLEDs, and the search of new efficient blue lightemitting materials is still urgent and essential.

\footnotetext{
* Corresponding author. Tel.: +38 0322582162.

E-mail address: stakhira@polynet.lviv.ua (P. Stakhira).
}

In this context, pyrazoline derivatives with good luminescence properties (with solution photoluminescence quantum yields up to $60-70 \%)[11,12]$ can be of interest for the application in OLEDs. Typically, small molecules show tendency of crystallization, which decreases the lifetime and luminescence capability of OLEDs. 1,3,5Triphenyl-4,5-dihydro-1H-pyrazol with phenyl group in position 5 of pyrazoline ring was found to form stable amorphous films by vacuum deposition [13]. A nonplanar molecular structure essentially prevents crystallization and thus decreases degradation of electroluminescent structure [14,15]. It was also reported [15] that the use of 2,6-di-tert.-butyl-4-(2,5-diphenyl-3,4-dihydro-2Hpyrazol-3-yl)-phenol (HPhP) (Fig. 1 (left)) as a hole-transporting layer results in the suppression of degradation processes in OLED under atmospheric factors. The aim of this work was to study the possibility of application of HPhP as a light-emitting layer in the OLED structure.

\section{Experimental}

2,6-Di-tert.-butyl-4-(2,5-diphenyl-3,4-dihydro-2H-pyrazol-3yl)-phenol (HPhP) [15] and 3,6-di(9-carbazolyl)-9-(2ethylhexyl)carbazole (TCz1) (Fig. 1 (right)) [16] were obtained as reported earlier. The gas phase molecular geometries of HPhP were optimized separately in the neutral and cationic states, by means of density functional theory (DFT) with hybrid exchange 


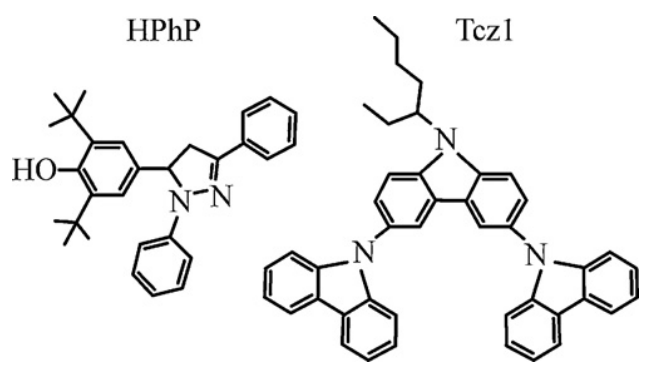

Fig. 1. Molecular structures of HPhP (left) and TCz1 (right).

correlation B3LYP functional with the average account of the exchange interactions contribution and with basis set 6-311G(d), which suffices for good correlation of the theory and experiment for molecules of such size. The calculations on the cationic species were performed using the unrestricted B3LYP formalism. Standard boundary conditions and algorithm were applied [17]. From ground state geometry singlet excited states energies and oscillator strengths of transitions were calculated by time dependent (TD DFT) (using B3LYP functional and $6-311 \mathrm{G}(\mathrm{d}, \mathrm{p})$ basis set) providing wavelengths for the majority of important transitions of the conjugated molecules. Transition condition reference was based on the excitation giving the basic contribution. Vertical electronic transitions spectra of the molecules were simulated using GaussSum 2.2 program [18]. Maxima in the computed spectra can be compared easily with the experimental data. Vertical ionization potential (IPv) values were also calculated as the energy difference between the energy of the cation in the neutral geometry and the neutral molecule in the neutral geometry; and adiabatic potentials (IPa) as the difference between the cation in the relaxed cation geometry and the neutral molecule in neutral geometry.

Using $\mathrm{HPhP}$, a multilayered light-emitting structure ITO/CuI $(12 \mathrm{~nm}) / \mathrm{HPhP}(25 \mathrm{~nm}) / \mathrm{TCz} 1(14 \mathrm{~nm}) / \mathrm{Ca}$ :Al was fabricated. Its energy diagram is presented in Fig. 2. Copper iodide (CuI) was used as the hole injection layer [19,20]. 3,6-Di(9-carbazolyl)-9-(2ethylhexyl)carbazole (TCz1) served as the electron-transporting layer. The choice of this material was based on its relatively high electron mobility $\left(2 \times 10^{-4} \mathrm{~cm}^{2} / \mathrm{Vs}\right)$ [16] exceeding by one order of magnitude the value of hole mobility, high thermal stability [16,21], and good energetical compatibility with Ca electrode (Fig. 2) [22]. The device was fabricated by means of vacuum deposition onto a precleaned ITO coated glass substrate under vacuum of $10^{-5}$ Torr. The thickness of the CuI, HPhP, and TCz1 layers was measured by ellipsometry technique [23]. For photoluminescence and absorption spectra measurements, the organic films were

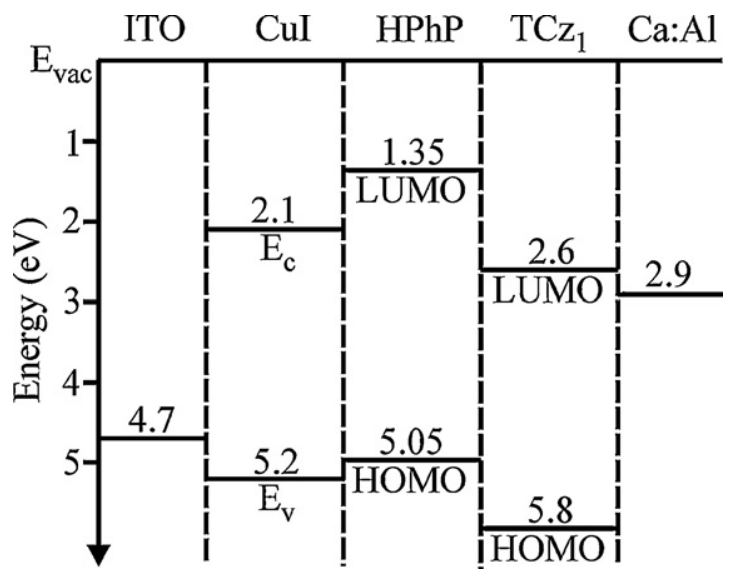

Fig. 2. Energy diagram of organic light-emitting diode made of ITO/CuI/HPhP/TCz1/Ca:Al. thermo vacuum deposited on quartz substrate. Absorption spectra were recorded with a Shimadzu UV-2450 spectrophotometer. Photoluminescence measurements were performed with a CM 2203 fluorimeter. The current density-voltage-luminance $(J-V-L)$ characteristics and electroluminescence (EL) spectra were measured using a Programmable Test Power LED300E, Spectrometer HAAS-2000, and an integrating sphere $(d=0.3 \mathrm{~m})$. It is well known that nowadays there are two different methods to determine the external quantum efficiency and other data of OLEDs. The first method, which is called the 'luminance-conversion method', evaluates the absolute luminance of a device using a conventional luminancemeter, and then converts luminance values into photon numbers. This method assumes a Lambertian emission pattern for perfect surface emitters, and is the simplest and widely used. However, far not all OLED emission patterns can be approximated with a simple Lambertian behaviour because of interference and other effects in the OLEDs. The second method, which is called the "direct-measurement method", directly evaluates the total absolute emission intensity of a device with a small emissive surface using calibrated photosensitive detectors. To accurately measure the absolute emission intensity, integrating spheres are often used. The direct external efficiency measurement method with integrated sphere was found to be more precise and useful as compared with usual luminance-conversion method [23]. For this reason we carried out measurements in an integrating sphere.

The measurements of cyclic voltammograms were carried out at a glassy carbon electrode in dichloromethane solutions containing $0.1 \mathrm{M}$ tetrabutylammonium perchlorate as electrolyte and $\mathrm{Ag} / \mathrm{AgNO}_{3}$ as the reference electrode. Each measurement was calibrated with ferrocene.

\section{Results and discussion}

To estimate the geometry and energy levels of HPhP and to check their matching with those of the neighbouring materials, calculations of molecular characteristics by means of a software package of quantum-chemical calculations (Gaussian 03) within the framework of the density functional theory (DFT) [24] were carried out. DFT and its time-dependent extension (TD-DFT) have emerged in recent years as a reliable standard tool for the theoretical study of geometrical and electronic properties of long conjugated organic molecules $[25,26]$. It is particularly useful in the studies of excited states.

The optimized molecular structure of HPhP is presented in Fig. 3. The studied molecule was found to be non-planar, hence capable to form stable amorphous films. The calculated spectrum for HPhP molecule (Fig. 3) has the similar shape and maxima compared to the experimental result [15]. The calculated band gap of the free HPhP molecule is ca. $3.7 \mathrm{eV}$ (comparable with the experimental value of ca. $3.45 \mathrm{eV}$ ) with the highest occupied molecular orbital (HOMO) and the lowest unoccupied molecular orbital (LUMO) of -5.048 and $-1.347 \mathrm{eV}$, respectively. The experimental HOMO $(5.085 \mathrm{eV})$ value (see Fig. 4) was found to be in good coincidence with calculations. The main orbitals (Fig. 3) show rather typical changes in the electron density distributions. Vertical ionization potential of free molecule is $6.192 \mathrm{eV}$ and adiabatic one is $6.054 \mathrm{eV}$. The calculated data were used in OLED energy diagram (Fig. 2).

Absorption (curve 1) and photoluminescence (curve 2) spectra of the structure $\mathrm{HPhP} / \mathrm{TCz} 1$ are presented in Fig. 5a. The absorption spectrum has two maxima at 342 and $366 \mathrm{~nm}$ as a result of the superposition of absorption by TCz 1 and HPhP. These maxima correspond to the vibronic bands of the first electron transition $\left(\mathrm{S}_{0}-\mathrm{S}_{1}\right)$ of single carbazole moiety $[21,27]$ and pyrazoline ring $[15,28]$. Photoluminescence spectrum of the structure HPhP/TCz1 (Fig. 5a, curve 2 ) is also a superposition of the luminescence spectra of TCz1 and 

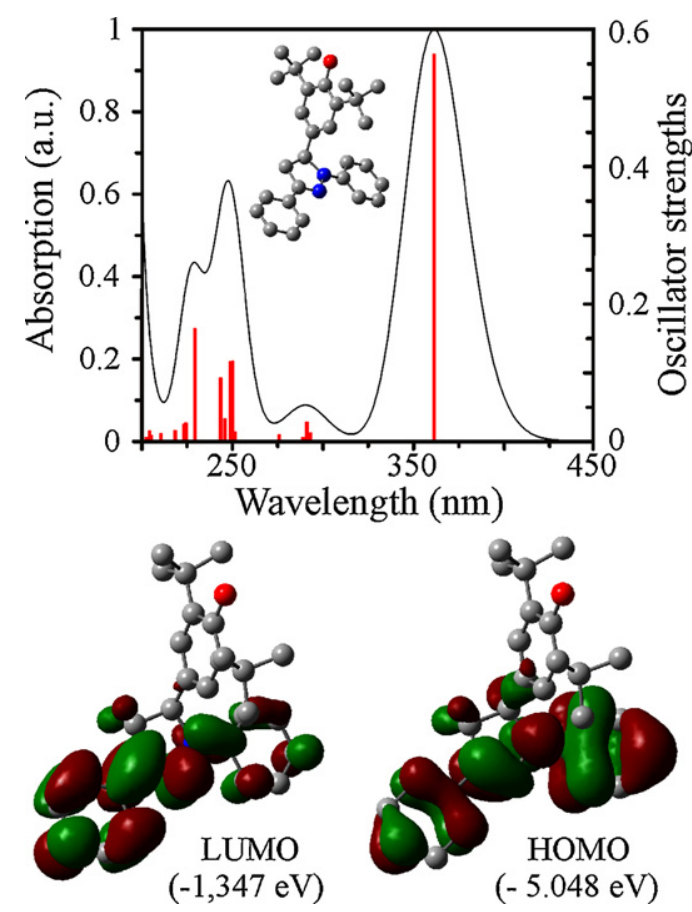

Fig. 3. Optimized molecular structure of HPhP, calculated absorption spectrum, and LUMO and HOMO electron density distributions.

HPhP. The shortwave shoulder in the region of $380-420 \mathrm{~nm}$ can be explained by vibronic transitions in TCz1 [16]. The long-wave maximum belongs to LUMO-HOMO radiative transition in $\mathrm{HPhP}$ molecule.

In contrast to photoluminescence spectrum the electroluminescence spectrum of the structure ITO/CuI/HPhP/TCz1/Ca:Al (Fig. 5b) is characterized by only a single maximum $\left(\lambda_{\max }=445 \mathrm{~nm}\right)$, which corresponds to HPhP photoluminescence maximum confirming the fact that radiative recombination of charge carriers occurs only within $\mathrm{HPhP}$ layer, and TCz1 layer acts only as an electrontransporting one. No spectral shift has been observed with current density changes. Electroluminescence is also characterized by a narrow spectral distribution (spectral halfwidth is $75 \mathrm{~nm}$ ), which is lower than the typical value. For the considered structure, the obtained colour CIE coordinates $(0.175,0.11)$ correspond to pure blue colour. It is worth of noting that, in contrast to TCz1, the

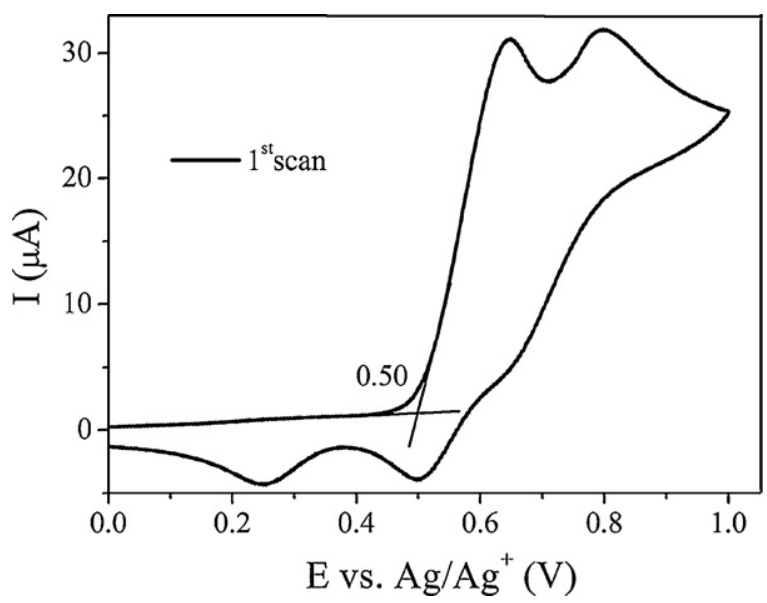

Fig. 4. Cyclic voltammograms of $\mathrm{HpPh}$ measured at scan rate of $50 \mathrm{mV} \mathrm{s}^{-1}$ (from $0 \mathrm{~V}$ to $1.0 \mathrm{~V})$ vs. $\mathrm{Ag} / \mathrm{Ag}^{+}$in a solution of TBAP $(0.1 \mathrm{M})$ in $\mathrm{CH}_{2} \mathrm{Cl}_{2}$. $\mathrm{E}_{\text {Hомо }}$ was found as follows: $\mathrm{E}_{\mathrm{HOMO}}=4.8+\mathrm{E}_{\text {onset }} \mathrm{Vs}$. $\mathrm{Fc}$, where $\mathrm{E}_{\text {onset }} \mathrm{Vs}$. $\mathrm{Fc}=\mathrm{E}_{\text {onset }}-\mathrm{E}(\mathrm{E}=0.215 \mathrm{~V})$, and $\mathrm{E}_{\text {onset }} \mathrm{Vs} . \mathrm{FC}=0.5-0.215=0.285 \mathrm{~V}$.
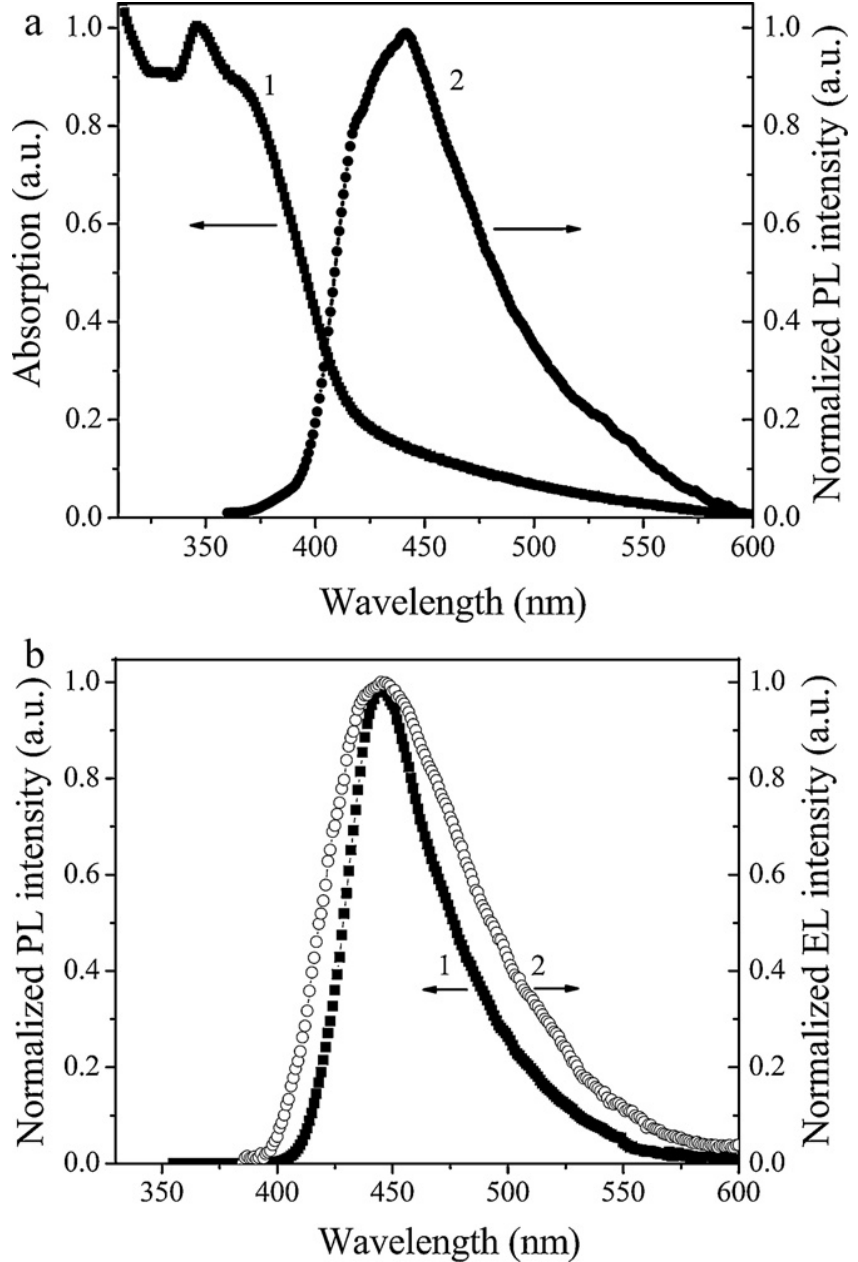

Fig. 5. Absorption (curve 1) and photoluminescence (curve $2, \lambda_{\mathrm{ex}}=300 \mathrm{~nm}$ ) spectra of HphP/TCz1 (a) and photoluminescence spectrum of the layer of $\mathrm{HPhP}$ (curve $1, \lambda_{\text {ex }}=300 \mathrm{~nm}$ ) and electroluminescence spectrum of the structure ITO/CuI/HPhP/TCz1/Ca:Al (curve 2) (b).

attempts of using conventional electron transporting $\mathrm{Alq}_{3}$ layer with $\mathrm{HPhP}$ resulted in typical green emission of $\mathrm{Alq}_{3}$ [15].

The current density-voltage curve of the device shows a turnon voltage $V_{\text {on }}$ of $9.4 \mathrm{~V}$ (Fig. 6a), which is rather high. Commonly, threshold voltage is determined by the structure thickness, film conductivity and injection barriers. The first two parameters are favourable in this structure (low thickness, good conductivity) however the injection barrier for holes is rather high as it is evident from Fig. 2. The maximal brightness of $1450 \mathrm{~cd} / \mathrm{m}^{2}$ is observed at $15.5 \mathrm{~V}$ (Fig. 6a). The bias increasing results in the reduction of the device brightness, followed by structural degradation.

Fig. 6b shows efficacy of ITO/CuI/HPhP/TCz1/Ca:Al electroluminescent structure. It can be noted, that organic layers are rather thin and do not essentially affect the performance due to optical effects. The maximal ratio of the brightness $\left(1035 \mathrm{~cd} / \mathrm{m}^{2}\right)$ to the current density $\left(9.74 \mathrm{~mA} / \mathrm{cm}^{2}\right)$ gives an efficacy level as high as $10.63 \mathrm{~cd} / \mathrm{A}$. This value is high for blue emitting fluorescent materials $[2,6]$. The reason of such efficacy is apparently raised from 3 times lower current densities at the same brightness as compared to typical devices. Low currents are observed in our electroluminescent structures containing only HPhP molecules used both as transporting (see [15]) and luminescent material. Thus, the observed efficacy value is determined by HPhP molecule. It can be supposed that $\mathrm{OH}$-group in this molecule not only improves the device stability, but also affects a charge transporting or 

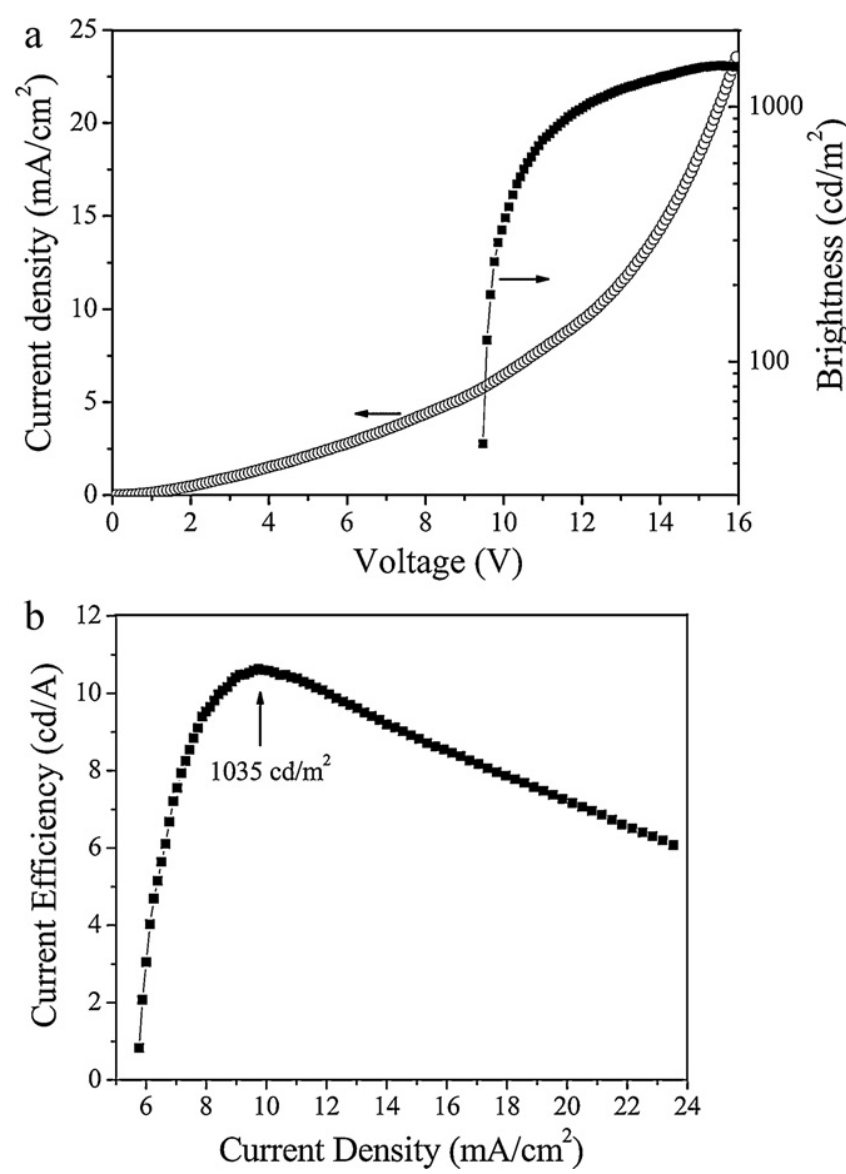

Fig. 6. OLED characteristics of the device ITO/CuI/HPhP/TCz1/Ca:Al: voltage-ampere characteristic (a), and voltage-brightness characteristic (b).

recombination properties, though OH-group is not involved in HOMO-LUMO transition (see Fig. 3). Actually, recombination zone of ITO/CuI/HPhP/TCz1/Ca:Al structure is located within HPhP layer as compared to $\mathrm{ITO} / \mathrm{CuI} / \mathrm{HPhP} / \mathrm{Alq}_{3} / \mathrm{Ca}$ :Al diode owing to higher TCz1 electron mobility [16] and gap than that of $\mathrm{Alq}_{3}$. On the other side, optical properties of HPhP and PhP molecules are almost the same, but currents in OLEDs are very different [15]. Thus, it can be supposed that the reason of higher efficacy of HPhP based OLEDs is better balance of charge carriers or recombination conditions. We can notice that one of the last efficiency values for fluorescent OLEDs is as high as 9.4\% [6] and exceeding theoretical predictions. Thus, many processes in OLEDs are not fully studied yet and this interesting question is still under study.

\section{Conclusion}

In conclusion, we have developed blue OLED with the configuration ITO/CuI/2,6-di-tert.-butyl-4-(2,5-diphenyl-3,4-dihydro-2Hpyrazol-3-yl)-phenol(HPhP)/3,6-Di(9-carbazolyl)-9-(2-ethylhexy1) carbazole (TCz1)/Ca:Al which exhibits an emission peak at $445 \mathrm{~nm}$ and colour CIE coordinates of $(0.175,0.11)$ with a high efficacy of $10.63 \mathrm{~cd} / \mathrm{A}$. We have demonstrated that light emission is observed from HPhP layer, whilst the layer of TCz1 acts as the electron transporting layer. The HPhP geometry configuration and energy levels have been found in the framework of DFT approach, which are in agreement with available experimental data.

\section{Acknowledgements}

This research was partially funded by a grant no. MIP-059/2011 from the Research Council of Lithuania, NRF-RF-2009-09 and NRF-CRP-6-2010-2 of Singapore, and State Fund for Fundamental Researches of Ukraine.

\section{References}

[1] A.V. Kukhta, J. Appl. Spectrosc. 70 (2003) 165-194.

[2] Z. Ma, P. Sonar, Z.-K. Chen, Curr. Org. Chem. 14 (2010) 2034-2069.

[3] Y. Liu, X. Tao, F. Wang, X. Dang, D. Zou, Y. Ren, M. Jiang, Org. Electron. 9 (2008) 609-616.

[4] Y. Sato, S. Ichinosawa, H. Kanai, IEEE J. Sel. Top. Quant. Electron. 4 (1998) 40-48.

[5] A.C. Grimsdale, K.L. Chan, R.E. Martin, P.G. Jokisz, A.B. Holmes, Chem. Rev. 109 (2009) 897-1091.

[6] C.-G. Zhen, Y.-F. Dai, W.-J. Zeng, Z. Ma, Z.-K. Chen, J. Kieffer, Adv. Funct. Mater. 21 (2011) 699-707.

[7] J. Wang, W. Wan, H. Jiang, Y. Gao, X. Jiang, H. Lin, W. Zhao, J. Hao, Org. Lett. 12 (2010) 3874-3877.

[8] D. Thirion, J. Rault-Berthelot, L. Vignau, C. Poriel Synthesis, Org. Lett. 13 (2011) 4418-4421.

[9] N. Cocherel, C. Poriel, L. Vignau, J.-F. Bergamini, J. Rault-Berthelot, Org. Lett. 12 (2010) 452-455.

[10] A.L. Fischer, K.E. Linton, K.T. Kamtekar, C. Pearson, M.R. Bryce, M.C. Petty, Chem. Mater. 23 (2011) 1640-1642.

[11] Z. Lu, Q. Jiang, W. Zhu, M. Xie, Y. Hou, X. Chen, Z. Wang, D. Zou, T. Tsutsui, Synth. Met. 111-112 (2000) 425-427.

[12] M. Jin, Y.J. Liang, R. Lu, X.H. Chuai, Z.H. Yi, Y.Y. Zhao, H.J. Zhang, Synth. Met. 140 (2004) 37-41.

[13] X.H. Zhang, S.K. Wu, Z.Q. Gao, C.S. Lee, S.T. Lee, H.-L. Kwong, Thin Solid Films 371 (2000) 40-46.

[14] X.H. Zhang, W.Y. Lai, T.C. Wong, Z.Q. Gao, Y.C. Jiang, S.K. Wu, H.L. Kwong, C.S. Lee, S.T. Lee, Synth. Met. 114 (2000) 115-117.

[15] V. Cherpak, P. Stakhira, S. Khomyak, D. Volunuyk, L. Voznyak, Z. Hotra, V. Sorokin, A. Rybalochka, O. Oliynyk, Opt. Mater. 33 (2011) 1727-1731.

[16] A. Tomkeviciene, J. Grazulevicius, A. Gruodis, T.-H. Ke, C.-C. Wu, K. Kazlauskas, J. Phys. Chem. C 115 (2011) 4887-4897.

[17] N.M. O'Boyle, A.L. Tenderholt, K.M. Langner, J. Comput. Chem. 29 (2008) 839-845.

[18] P. Stakhira, V. Cherpak, D. Volynyuk, F. Ivastchyshyn, Z. Hotra, V. Tataryn, G. Luka, Thin Solid Films 518 (2010) 7016-7018.

[19] G. Luka, P. Stakhira, V. Cherpak, D. Volynyuk, Z. Hotra, M. Godlewski, E. Guziewicz, B. Witkowski, W. Paszkowicz, A. Kostruba, J. Appl. Phys. 108 (2010) 064518.

[20] M.-H. Tsai, Y.-H. Hong, C.-H. Chang, H.-C. Su, C.-C. Wu, A. Matoliukstyte, J. Simokaitiene, S. Grigalevicius, J.V. Grazulevicius, C.-P. Hsu, Adv. Mater. 19 (2007) 862-866.

[21] V.V. Cherpak, P.Y. Stakhira, D.Yu. Volynyuk, J. Simokaitiene, A. Tomkeviciene, J.V. Grazulevicius, A. Bucinskas, V.M. Yashchuk, A.V. Kukhta, I.N. Kukhta, V.V. Kosach, Z.Yu. Hotra, Synth. Met. 161 (2011) 1343-1346.

[22] O. Aksimentyeva, V. Beluh, D. Poliovyi, V. Cherpak, P. Stakhira, D. Volynyuk, Mol. Cryst. Liq. Cryst. 467 (2007) 143-152.

[23] I. Tanaka, S. Tokito, Jap. J. Appl. Phys. 43 (2004) 7733-7736.

[24] M.J. Frisch, G.W. Trucks, H.B. Schlegel, et al., Gaussian 03, Revision D.01, Gaussian, Inc., Wallingford, CT, 2004.

[25] A. Vlček Jr., S. Záliš, Coord. Chem. Rev. 251 (2007) 258-287.

[26] A.V. Kukhta, I.N. Kukhta, S.A. Bagnich, S.M. Kazakov, V.A. Andreev, O.L. Neyra, E. Meza, Chem. Phys. Lett. 434 (2007) 11-14.

[27] J. Simokaitiene, S. Grigalevicius, J.V. Grazulevicius, R. Rutkaite, K. Kazlauskas, S. Jursenas, V. Jankauskas, J. Sidaravicius, J. Optoelectron. Adv. Mater. 8 (2006) $876-882$.

[28] P. Zhao, R. Li, H. Wang, F. Jian, H. Guo, Spectrochim. Acta A 74 (2009) 87-93. 